\title{
HYPERTROPHIED TONSILS AND ADENOID VEGETATIONS IN PUBLIC SCHOOL-CHILDREN IN NEW YORK CITY.*
}

\author{
Dr. S. Joslipulin\} Bakik, New York City.
}

At a meeting of the Laryngological Section of the Academy of Medicine on March 26, a motion was passed authorizing the Secretary to send to each nember a circular letter embodying certain questions regarding the relation between the Board of Health, through its school medical inspectors, and the occurrence of hypertrophied tonsils in public school children. Later, this report was used by the Public Education Association as the basis of resolutions which were sent to the Board of Health, asking that the inspectors recommend, in each case of hypertrophied tonsils, whether or not operation should be performed.

Section on Laryngology \& Rhinology of the New York Academy of Medicine. on Laryngology \& Rhinology of the New York Academy of
Associated out-Patjents Clinics of the City of New York,
17 West 43 rd Street. CITY. 17 West 43rd Street, CITY. of New York,
New York, April 23, 1913.

Dear Sirs: Desiring to comply with your request for an expression of opinion from
the members of the Laryngological Section upon certain phases of the "Tonsil Situation" in this city, the matter was brought before the section at the regular moeting on March 26. On motlon, the Secretary was incontained in your communication. alrcular letter embodying the questions and the folloyvin communication. Some seventy responses were received. and the following report embraces tho opinion of the majority of those who answered this letter.

Ruestion 1: Should the present widespread practice of tonsllectomy in rents to have their chlldren's tonsils removed? encouraged in urging pa-

specially trained to recognize in children should bo advised only by those Theclally trained to recognize the condlions demanding tlis operation. (b) The average school inspector and visiting nurse is incompotent to decide this question. (c) Parents should not be advised to take their children to certain Institutions as this encourages many to seek charity who otherwise favor ton tomy still has its in every instance, but some few belleve that tonsllec. Question has its place.

Question 2: Should either tonslllectomy or tonslllotomy, or both, be per-
cormed in Out-Patient Clinics?

Answer: (a) The majority believe that both operations are operations requiring the facllities of a hospital. (b) A small minority bellove that foth operations can be safely done in an Out-Patient Clinic, while some lew believe that tonslllotomy, but not tonsllectomy, may be done without ospital facllitles.

Question $3:$ If the previous question is answered in the affimative, what facilities should be provided for the surgical treatment and after-care of these patients? Should operations be performed in dispensaries (a) which have no special operating room (b) which have no recovery room where patients may be kept after operation?

Answer: The few who think that this operation can be safely performed in a dispensary, belleve that a recovery room should be provided where patients may be kept for several hours under observation.
Yours very truly,

Signed C. D. VAN WAGRNEN, M. D.

Signed, WILLTAM WISLEY CARTER, Mr, D. Secretary.

Chairman.

The answers to the questions sent out by this Section seem to me to indicate a misunderstanding in regard to the Department of

* Read before the Section on Laryngology and Rhinology of the $N$. $Y$. Academy of Medicine, Decimber 17, 1918. 
Health, and therefore it is my desire to place the facts clearly before you. The importance of this subject merits consideration, as the department, through its school medical inspectors, supervises the health of 825,000 school children of this city. Since 1905, the system of school medical inspection has included the physical examination of each child on its entrance to school and on an average of every three years thereafter. School inspectors are all appointed from lists furnished by the Civil Service Commission, and are all physicians licensed to practice in the State of New York. The majority are graduates of New York City Colleges.

During the early part of this work it was reported by these inspectors that approximately thirty per cent of the children in the schools were suffering from hypertrophied tonsils, with or without a form of obstruction to the nasal breathing which implied the presence of adenoid growth. It was the desire of the department to fix a stanclarcl, as far as possible, for the class of cases where operation would be advisable, and to this end a letter was sent to a number of eminent specialists in nose and throat diseases in this city, asking them what, in their opinion, were the exact indications for the operative treatment of enlarged tonsils. It was a significant fact that no two of these specialists agreed as to the exact details; most of them dwelt upon many features of this condition which, from the standpoint of the medical inspector, were not practical. The opinions expressed by them revolved about the following points: size of the tonsil, adhesion to the pillars of the fauces, smoothness of the surface or the presence of large and irregular crypts, the embedded tonsil, the pathological tonsil, the tonsil which was subject to frequent attacks of acute inflammation, the susceptibility of children, because of this enlargement, to infectious diseases, and the question as to whether the tonsil was hypertrophic or hyperplastic. There was no tunanimity of opinion, nor was any statement made that was practical to apply to the work of medical inspection of school children. In fact, it cotld readily be gathered from the statements made by them that if a set of one hundred children with enlargement of the tonsils was submitted to these seven specialists, no agreement could be reached between them as to the indications for operation in these cases.

Realizing, then, the marked clifference in opinion that must be considered even in the diagnosis of these cases, the Burean of Child Hygiene established a standard as follows: that no ease was to be considered as true hypertrophy of the tonsils unless the hypertrophy was such as to interfere with the nutrition of the child or to cause 
secondary clisturbances, interfering with its health and, incidentally, with its school progress. In other words, no tonsil was to be considered hypertrophic unless the medical inspector, considering it as his personal case, believed that its presence was a distinct' detriment to the health of the child, and that, therefore, the tonsil should be removed. At no time has the medical inspector been allowed to indicate the character of treatment that should be considered advisable. 'The Department of Health has always taken the attitucle in regard to the inspection of school children that its duties consist in ascertaining defects which interfere with the health of the children, calling the attention of the parents to the fact that the children are so affected, and making all possible efforts to see that the children in question are placed under competent medical care. The Department does not feel that it should dictate the character of treatment to be obtained by the child but holds that this is a matter which should be left to the attending physician. It also believes that its functions and efforts should not extend beyond seeing that the parents are made to realize their responsibility in regard to the welfare of their children and that the latter are placed under medical care. For this reason a certificate from a physician or surgeon, stating that a child is under his care, has always been accepted by the department as evidence of treatment, although the department realizes from extensive experience the futility of socalled "medical treatment" in the cure of either enlarged tonsils or adenoids.

Since January 1, 1909, the Bureau of Child Hygiene has kept accurate and careful records of the occurrence of these cases among the school children of this city, and it is interesting to note, that whereas in 1909, 22 per cent of the children in the public schools were found to have hypertrophied tonsils, in 1912 only 10.14 per cent were found to be so affected. 'T'he reduction in the number of cases of defective nasal breathing, with possible adenoids, has been even greater, or from 18.7 per cent in 1909 to 7.6 per cent in 1912.

Statements (a) and (b), therefore, as outlined in your report, are founded on a misapprehension, for when it is stated that (a) "tonsillectomy in children should be advised only by those specially trained to recognize the conditions clemanding this operation" and (b) "the average school inspector and visiting nurse is incompetent to decide this question" it should be realized that this latter assumption is based upon conditions which do not exist, as the inspectors do not recommend treatment, but simply state that an 
abnormal condition is present, and then the matter is referred to the family physician for such action as he may deem advisable.

The first question, "Should the present widespread practice of tonsillectomy in school children be continued, and the school inspectors encouraged in urging parents to have their children's tonsils removed?" seems also to be founded upon a misapprehension. I would call your attention to the fact that, in 1912 , out of 287,469 children examined, 30,021 (or 10.4 per cent were found to have hypertrophied tonsils. Of this latter number, 14,13\% (or only $4 \% .1$ per cent) obtained treatment. The character of this treatment, according to the certificates of the physicians and surgeons who administered it, was as follows: Operations, 6,239 or 20.5 per cent; medical treatment, 7,898 or 26.3 per cent.

Of the total number of children with tonsils so enlarged that the nutrition and well-being of the child were seriously interfered with, only 20 per cent had the tonsils removed. 'This hardly seems to warrant the iclea that there is a widespread operating for partial or complete removal of tonsils.

No attempt is made by the medical inspector to diagnose adenoids. It is not possible, in the ordinary school building, to provide facilities for a proper examination of the naso-pharyngeal vault and therefore, for many years, the department has not used the term "adenoids" in its report of the physical condition of school children, but each child has been tested to determine whether or not its nasal breathing was occluded. In each such case, a diagnosis of defective nasal breathing has been made, and it has been left for the family physician to decide whether or not this occlusion was due to adenoids, deflected septum, hypertrophied turbinate, nasal polypi, or other cause, and to provicle appropriate treatment.

The second and third questions of your report, relating to whether or not tonsillectomy on tonsillotomy should be performed in outpatient clinics, are of particular interest to this department becatuse several years ago, our expericence of the results of operating upon these children in dispensaries, and without anesthesia, and sending them home immediately after operation, was such as to lead us to believe that additional hospital facilities must be provided and that, eventually, operations in clispensaries would cease because of their freçuently harmful nature. 'The shock to the nervous system of the child, as a result of having this operation performed without anesthesia, the fact that in many instances the struggles of the child prevents the operation being either a complete or a partial. success, the danger of septic sore throat and the more marked dan- 
ger of secondary hemorrhage, are results which have been noted by the department's inspectors and nurses in no inconsiderable number of cases. 'There are, in this city, a large number of people who are unable to pay the fee required for the use of an operating room or the anesthesia, and, possibly, the cost of remaining in a hospital, yet whose children are urgently in need of this operative care. While the Borough of Manhattan is fairly well supplied with hospitals and dispensaries, the other boroughs are not so well cared for and it is often impossible for a school child to go to a dispensary at ary great clistance, owing to the fact that its parents are frequently unable to accompany it. The Children's Clinics maintained by the Department of Health, therefore, have been placed only in those parts of the city where the need was evident and where the existing facilities were insufficient to care for the number of children needing treatment and unable to pay for it. The greater need, however, which was covered by the establishment of these dispensaries was the provision of a place where a child might be adequately cared for during its operation.

Before sending a child to one of these clinics, the nurse investigates the financial status of the family, and children are not referred for treatment unless the family is unable either to pay a private physician or the requisite fee for hospital care. After a child is received at the clinic, a further investigation as to the financial status of the family is made by the registrar. The clinics are operated under the control of the State Board of Charities, and the department makes every possible effort to see that the facilities are extended only to those children whose parents are umable to pay any fee.

In our clinics all children are received the afternoon before the day of operation; they are kept there that night, regularly prepared for operation, and the following morning the adenoids or tonsils are removed under gas and ether anesthesia. 'l'he child is then kept in bed during that day, remains in bed the following night, and is finally discharged thirty-six or forty-eight hours after entrance. Nearly four thousand such operations have been performed since the dispensaries were opened, with one fatality. 'This latter was the case of a girl, 11 years old, who was mentally defective. She was operated tupon at 10 o'clock in the morning, about two hours later became cyanotic, reacted well to stimulation, and showed improvement until about 3 o'clock in the afternoon, when she again became cyanotic, developed an exceedingly rapid pulse, and died suddenly. There was hemorrhage from the throat just before 
death. In every other instance the child has left the hospital in good condition and has remained so.

From our experience with these children, we believe that these operations should never be performed except under anesthesia and that, in each case, the child should remain in the hospital for twentyfour hours after the operation has been performed.

In order that the school children of this city may receive the care to which they are entitled so that they may reach normal development in adult life, it is essential that everyone connected with this problem should realize the necessity of harmonious and co-operative work. In the care of school children there are many factors involved: first, the Board of Iiducation, which has charge of the school buildings and the conditions under which the children study; second, the Department of Health which has charge of the school medical inspection and examination; third, the medical profession, who must malie the ultimate diagnoses and provide for treatment; fourth, the parents, who must be convinced of the necessity of proper care for the child, and, last and most important of all, the child himself, towards whom our efforts are directed. Unless there is complete understanding, unless there is a realization of definite good to be clone, we shall all fail of our purpose, but if each will do his part, with a realization that there is a part for each to do, the status of the school child, as far as its physical conclition is concerned will be inevitably and materially improved.

33 West Ninety-sixth Street.

Treatment of Diphtheria and Diphtheria varriers. SoI.ON G. WiLson, New Orleans Med. and Surg. Jour., Sept., 1913.

The best results in the treatment of the disease is by large doses of concentrated antitoxin, 10,000 units being the initial close, given intra-mascularly, with a period of twenty-four hours between the doses, the membrane being the chief guide of repeating the dose, except, of course, in the laryngeal type, and in this type the stenosis and cyanosis serving as a guide. Owing to the frequency of diphtheria carriers, cultures are advised before tonsillectomies and adenectomies. 